\title{
Poder Judiciário e Competição Política: as eleições de 2010 e a lei da "ficha-limpa"
}

\begin{tabular}{c}
\hline \hline Joaquim Falcão \\
Escola de Direito \\
Fundação Getúlio Vargas \\
Fabiana Luci de Oliveira \\
Escola de Direito \\
Fundação Getúlio Vargas \\
\hline \hline
\end{tabular}

\begin{abstract}
Resumo: 0 objetivo é discutir a percepção do brasileiro em relação ao papel do Poder Judiciário no processo de competição política e as consequências desta percepção para a governança eleitoral. Para isso, exploramos as eleições ocorridas em outubro de 2010 e o episódio da lei da "ficha limpa". Ao contrário da maioria dos estudos correntes que focam na percepção do Judiciário como instituição única, abordamos as especificidades da justiça eleitoral como poder político e prestador de serviço público - lembrando que a justiça eleitoral atua não apenas resolvendo litígios mas organizando e realizando o processo eleitoral. Adicionamos novos elementos empíricos a uma questão antiga: o brasileiro confia ou desconfia do Poder Judiciário? Nosso argumento é de que quando se trata da organização e fiscalização das eleições, o brasileiro confia no Judiciário como garantidor da realização e lisura do processo eleitoral. Mas quando se trata da resolução de conflitos, o brasileiro tende a desconfiar do Judiciário - lento, caro e de difícil acesso. O nível educacional é decisivo para determinar esta percepção - quanto maior o nível educacional, mais favorável a visão do Judiciário. A base para a discussão é dada pelos resultados de um survey conduzido pela FGV Direito Rio uma semana após o segundo turno das eleições de outubro de 2010.
\end{abstract}

Palavras-chave: Poder Judiciário; justiça eleitoral; confiança institucional; competição política; eleições; ficha-limpa

Abstract: The goal is to discuss the public perception regarding the role of the judiciary in the political electoral process and the consequences of this perception to the electoral governance. We explore the Brazilian 2010 elections and the episode of the "clean slate law". Unlike most current studies that focus on perception of the judiciary as a single institution we discuss the specificity of electoral justice as a political power and a public service provider - considering that the electoral judiciary operates, not only resolving electoral disputes but organizing and conducting the electoral process. We add new empirical evidence to an old question: do Brazilians trust or distrust the judiciary? Our argument is that when it comes to the organization and supervision of elections, Brazilians are confident in the judiciary as a guarantor of the fairness of the electoral process. But when it comes to conflict resolution, Brazilians tend to distrust the judiciary - slow, expensive and difficult to use. The educational level is decisive for this perception - the higher the educational level, the more favorable view of the judiciary. The basis for our discussion is given by the results of a survey conducted by FGV Law School a week after the second round of 2010 elections.

Keywords: Judicial Power; electoral justice; institutional trust; political competition; elections; clean slate law 
OPINIÃO PÚBLICA, Campinas, vol. 18, n², novembro, 2012, p. 337-354

\section{O Poder Judiciário Eleitoral ${ }^{1}$}

O objetivo deste artigo é discutir a percepção do brasileiro com relação ao papel do Poder Judiciário no processo político eleitoral. Mas, antes, faz-se necessário constatar a diferenciação interna do Poder Judiciário em diversas justiças e competências, com destaque para a justiça eleitoral.

Os estudos correntes no Brasil indicam que a sociedade e a opinião pública percebem o Poder Judiciário como lento, caro, difícil de utilizar, parcial e muitas vezes corrupto (SADEK, 2004; UNITED NATIONS, 2005; FALCÃo 2009; CUNHA et al, 2010; IPEA, 2010). Essa visão, segundo SADEK (2004), é corrente também entre segmentos da elite, com cerca de $89 \%$ do empresariado brasileiro avaliando o Judiciário como "ruim" ou "péssimo" em termos de agilidade.

Pesquisas sobre confiança nas instituições democráticas colocam o Judiciário brasileiro numa posição crítica - a instituição só não é menos confiável que as instituições políticas representativas: partidos políticos, senado e câmara dos deputados (MoIsÉs, 2005; CUNHA et al, 2010).

O índice de confiança na justiça desenvolvido por Cunha et al (2010), por exemplo, mede a percepção da população em relação ao Judiciário a partir de nove dimensões: 1) confiança espontânea, 2) velocidade na prestação jurisdicional, 3) custo do acesso, 4) facilidade do uso, 5) imparcialidade, 6) honestidade, 7) competência na solução dos casos, 8) desempenho atual do Judiciário comparado aos últimos 5 anos e 9) expectativas para o desempenho futuro do Judiciário nos próximos 5 anos. 0 resultado é uma medida síntese destas dimensões: dos 10 pontos possíveis, o índice de confiança na justiça atinge apenas 4,4 pontos, o que significa que o brasileiro confia muito pouco na justiça brasileira.

No sistema de indicadores de percepção social do IPEA (2010), a nota média que a justiça brasileira alcança é também extremamente baixa: são 4,55 pontos (de 10 possíveis). A pesquisa explorou seis dimensões da justiça: 1) velocidade na decisão de casos; 2) acesso; 3) custo; 4) qualidade das decisões; 5) honestidade e 6) parcialidade. Em todas elas a justiça deixa a desejar aos olhos do cidadão.

Estes estudos corroboram o diagnóstico geral que vem sendo discutido nas últimas décadas de que o Judiciário brasileiro tem apresentado historicamente pouca capacidade de resposta aos anseios e demandas sociais (MACHADO, 1994; SADEK, 2004).

Mas é importante atentar que a maioria deles se preocupou em mensurar aspectos ligados especificamente ao desempenho e à eficácia administrativa do Judiciário, tratando o Judiciário de maneira geral, sem especificar a qual competência constitucional, e a qual tipo de justiça, referiam-se. Tratando, portanto, o Poder Judiciário como instituição una.

O estudo de Falcão (2009) diferencia-se ao procurar entender a que justiça os brasileiros referem-se quando fazem sua avaliação e constata que há uma diferença na avaliação de desempenho das diversas justiças, sendo as que estão mais próximas e mais vinculadas aos interesses dos cidadãos, como a justiça do trabalho e os juizados especiais, as mais bem avaliadas.

\footnotetext{
${ }^{1}$ Gostaríamos de agradecer a leitura cuidadosa e os comentários que Feliciano Guimarães, Mario Machado e Pedro Abramovay fizeram à versão preliminar deste artigo.
} 
FALCÃO, J.; OLIVEIRA, F. L. Poder Judiciário e Competição Política: as eleições de 2010...

O Brasil tem hoje noventa e três tribunais, diversos em suas especializações e em suas competências político-jurídicas ${ }^{2}$. Se considerarmos que cada tribunal goza, constitucionalmente, de autonomia administrativa, diferenciadas são, portanto, as respectivas governanças, desempenhos e inclusive as relações com os demais poderes da República. Sejam poderes do âmbito federal, estadual ou municipal.

É, pois, razoável supor que, na medida em que se aprofundem estudos empíricos sobre as competências específicas de determinados tipos de justiça, cresça a diferenciação nos índices de confiança dos cidadãos em relação a estas justiças e aos diversos judiciários. Entender este processo de diferenciação pressupõe a constatação de que: (a) a Constituição criou um Poder Judiciário integrado por múltiplos e diferentes tribunais, (b) cada tribunal tem, em princípio, três competências distintas: a competência administrativa, a regulatória e a jurisdicional.

Na verdade, cada país, em cada momento histórico, decide quantos poderes de Estado terá - o Brasil já teve quatro poderes no Império - e atribui competências diversas, e muitas vezes concorrentes, a cada um destes poderes de acordo com o modelo de regime político que adota. É através destas competências, que têm uma dupla dimensão de poder e também de serviço público, que o Poder Judiciário organiza, modela e concretiza o ius imperium. Neste sentido, ele é tanto prestador de serviço público quanto um Poder de Estado (SADEK, 2004). Como poder, detém e estrutura o ius imperium. Como serviço, o exerce. A Constituição regula ambos e, ao fazê-lo, atribui competências diversas a cada tribunal.

A justiça eleitoral, por exemplo, diferencia-se das demais justiças no Brasil, e das justiças dos demais países. Além da competência de autoadministrar-se, e a jurisdicional, de resolver litígios eleitorais de terceiros, detém a competência de regular, organizar e fiscalizar a própria competição político-eleitoral. As competências de organização e fiscalização das eleições, em outros países, é, em geral, atribuída ao Poder Executivo e ao poder local. No Brasil, não; elas cabem ao Poder Judiciário Eleitoral. E o Supremo Tribunal Federal integra, como última e decisiva instância, este Poder Judiciário Eleitoral. Um poder com natureza de Judiciário e competência de Executivo também.

O significado de governança judicial da competição político-eleitoral é ampliado para incluir, pois, a realização e a administração das eleições. Quando se pesquisa a confiança dos cidadãos, ou do eleitor, no Poder Judiciário, a competência de organização e fiscalização eleitoral deve ser considerada.

A título meramente ilustrativo, considere-se que as demais justiças regulam e adjudicam litígios, por exemplo, de saúde pública. Mas não organizam a gestão da saúde pública - não fiscalizam hospitais, nem os resultados das internações, etc. Já a justiça eleitoral, de fato, administra as eleições. Apura e divulga os resultados. É o presidente do Tribunal Superior Eleitoral quem se apresenta ao eleitor na mídia como principal responsável pelo bom andamento das eleições. Comanda a polícia federal durante as eleições. Participa de, e lidera, uma governança judicial mais ampla.

${ }^{2}$ ADIN 3367 - são 27 TJs, 5 TRFs, 24 TRTs, 5 Superiores (incluindo o STF), 27 TREs, 5 Tribunais de Justiça Militar (SP, MG, RS, $P E, P R)$ 
OPINIÃO PÚBLICA, Campinas, vol. 18, n², novembro, 2012, p. 337-354

Marchetti e Cortez (2009) destacam esta participação ativa dos órgãos judiciais, da justiça eleitoral, na organização e gestão da competição política, a partir da interpretação e criação das regras que regulam essa competição. E, segundo Marchetti (2011), isso decorre do fato de o modelo de governança eleitoral adotado no Brasil ser judicializado e constitucionalizado.

É judicializado porque em todas as atividades relativas à governança há uma proeminência dos membros do Judiciário. Em nenhuma instância da Justiça Eleitoral há a participação de outras associações ou instituições de fora do universo jurídico, fato não raro na governança de outros países. Além do mais, a Justiça Eleitoral brasileira não conta com um corpo decisório permanente e exclusivo. Os juízes e/ou ministros que assumem funções na Justiça Eleitoral dividem seu tempo com suas atividades judiciais originais. É constitucionalizado porque a última instância da Justiça Eleitoral - o TSE. é composta por uma "regra de intersecção" com a Corte Constitucional - o STF. O TSE é composto por sete membros, três ministros do STF, dois ministros do STJ e dois cidadãos com notório saber jurídico e idoneidade moral indicados pelo STF e selecionados pelo Presidente da República (MARCHETTI, 2011, p.38).

Neste artigo, ao discutir como o brasileiro avalia o desempenho político do Judiciário levamos em consideração esta competência - da organização e gestão da competição político-eleitoral. Assim, perguntas como "o brasileiro confia no Poder Judiciário para cumprir seu papel político de fiscalizar os demais Poderes durante o processo eleitoral?" ou "o brasileiro confia que o Poder Judiciário possa planejar e executar o processo eleitoral de competição política?" são pertinentes e necessárias.

Ademais, quando se analisa o aspecto de poder político, é preciso levar em conta, com Caldeira e Gibson (1992), a vulnerabilidade dos tribunais em geral, e da Suprema Corte em especial, uma vez que estas instituições não são diretamente accountable. Ou seja, não têm a legitimidade do processo eleitoral. Juízes não são eleitos pelo voto popular. E como a Suprema Corte, algumas vezes, precisa decidir contra a opinião pública é preciso que haja uma espécie de "estoque" de confiança pública para que ela consiga manter a sua legitimidade mesmo após estas decisões e, mais ainda, para ter suas decisões respeitadas e seguidas.

Os autores partem da divisão proposta por Easton (1965 - apud CALDEIRA e GIBSON, 1992) entre apoio específico e apoio difuso para argumentar que é no apoio difuso que a corte consegue se manter em face de suas decisões impopulares. Easton define apoio específico como um conjunto de atitudes em relação a uma instituição baseada na percepção do cumprimento das exigências e expectativas em relação ao seu papel. No caso da justiça eleitoral, acreditamos que o apoio específico está muito diretamente vinculado ao exercício de sua competência de organizar e realizar eleições. Já o apoio difuso refere-se a um reservatório de atitudes favoráveis ou de "good will" voltado para o conjunto de competências da instituição e independe do desempenho dos seus membros ou instâncias.

Moisés $(2005,2010)$ utiliza esta mesma distinção de Easton para explicar o que chama de convivência contraditória entre desconfiança dos cidadãos nas instituições públicas e seu apoio à democracia. Um aspecto é a confiança na democracia como princípio normativo e significado ideal (apoio difuso) e outro é a percepção do seu desempenho concreto a partir de suas instituições (apoio 
FALCÃO, J.; OLIVEIRA, F. L. Poder Judiciário e Competição Política: as eleições de 2010...

específico). Esta mesma distinção de Moisés, se aplicada aos estudos sobre confiança na Justiça, explicaria a convivência contraditória entre a desconfiança no Poder Judiciário, decorrente da desaprovação de seu desempenho como serviço público ao decidir conflitos do cotidiano dos cidadãos, e do apoio à ideia e necessidade da existência de um terceiro poder, um Poder Judiciário, para controlar os demais poderes.

Dadas estas especificidades de como o Poder Judiciário estrutura-se, buscamos neste artigo entender se há diferença entre a percepção do desempenho do Judiciário Eleitoral no exercício de suas múltiplas competências (como poder político regulador, como solucionador de litígios decorrentes da competição política, e como organizador, fiscalizador e realizador das eleições) e a percepção sobre o desempenho do Poder Judiciário "geral", tal como abordado na maioria das pesquisas correntes, aquele que presta serviço ao cidadão comum, solucionando seus litígios.

Para enfrentar estas questões, utilizamos os dados do survey nacional "Poder Judiciário e Eleições 2010"3 , conduzido pelo Centro de Justiça e Sociedade da Escola de Direito da Fundação Getúlio Vargas no Rio de Janeiro. Foram entrevistados 1.300 eleitores entre os dias 05 e 09 de novembro de 2010. O survey foi desenhado com o objetivo de apreender a visão do brasileiro acerca do envolvimento do Poder Judiciário no processo eleitoral e mensurar a percepção quanto ao seu desempenho nas eleições de 2010, dando destaque especial ao episódio da validade da lei da "ficha limpa" (ver Falcão e Oliveira, 2011).

\section{As eleições de 2010}

Desde a Constituição de 1988, o Poder Judiciário vem ocupando um espaço cada vez maior na vida política brasileira, seja no processo de formulação e implementação de políticas públicas, seja na delimitação das atribuições dos demais poderes do Estado. Tem crescido também a centralidade do papel que este poder desempenha na definição e implementação das regras da competição político. eleitoral. O Ministro Ricardo Lewandowski, atual presidente do Tribunal Superior Eleitoral, costuma dizer que o século XIX foi o século do Parlamento, o século XX o do Executivo e o século XXI será o século do Judiciário.

Não é difícil encontrar no Brasil decisões dos tribunais superiores que demonstram este crescente papel do Judiciário na esfera eleitoral, não apenas interpretando como alterando as regras da competição política. Temos, por exemplo, importantes decisões judiciais em relação a temas como cláusula de barreira, fidelidade partidária, coligações eleitorais, número de representantes para câmaras municipais e estaduais. E, mais recentemente, o conflito entre o Supremo e o Congresso sobre os

\footnotetext{
${ }^{3}$ Disponível em: <http://direitorio.fgv.br/cjus/nucleo-pesquisa>. A amostra utilizada é representativa da população brasileira de 18 a 70 anos de idade, com acesso a telefone na residência e/ou local de trabalho. A definição da amostra foi feita em duas etapas: a primeira foi a verificação da distribuição da população brasileira por regiões (Norte, Nordeste, Sudeste, Centro-Oeste e Sul) de acordo com a PNAD 2009, para que o número de entrevistas em cada uma delas fosse rigorosamente igual a essa distribuição. Na sequência foi realizado o levantamento da população de cada município de acordo com a Contagem da População - realizada pelo IBGE em 2007, para verificar, dentro de cada região, a distribuição da população por porte de município (até 20 mil habitantes; mais de 20 a 100 mil e mais de 100 mil habitantes) e por condição do município (capital de unidade da Federação; regiões metropolitanas - menos a população das capitais - e interior - restante do país). A segunda etapa foi o estabelecimento de quotas de sexo, faixas etárias e anos de escolaridade, das pessoas de 18 a 70 anos de idade, de acordo com a distribuição verificada pela PNAD 2009.
} 
OPINIÃO PÚBLICA, Campinas, vol. 18, n², novembro, 2012, p. 337-354

critérios legais para a posse de suplentes. Um conflito no fundo sobre quem detém a palavra final sobre regras da competição política.

Ao confirmar, ainda que indiretamente, a validade da lei de "ficha limpa" para as eleições de 2010, o Supremo alterou profundamente o provável resultado da competição eleitoral caso a lei não tivesse sido aplicada. Nossas primeiras perguntas são se o eleitor percebeu, e se percebeu, como viu esta decisão do Supremo? Esta decisão jurisdicional influenciou sua percepção, e mais ainda, o seu voto?

A posição do Supremo resultou de um impasse interno na corte. Com apenas dez ministros em vez de onze, cinco declararam-se favoráveis à validade imediata da lei, e cinco contrários. Na última sessão do ano de 2010, na qual o plenário se reuniu para discutir o tema, permaneceu o impasse em relação ao critério de desempate. Quem e como desempataria? O impasse prosseguiu, então, em relação às regras regimentais do próprio Supremo. Por falta de uma maioria, acabou permanecendo a interpretação do TSE e, indiretamente, a lei de "ficha limpa" permaneceu válida nas eleições de 2010. Em suma, ao não decidir naquele momento, o Supremo decidiu".

A lei da "ficha-limpa", de acordo com Marchetti (2011), exacerbou o processo de judicialização da competição política, uma vez que adicionou critérios legais à definição da elegibilidade de candidatos. Direcionou parte da estratégia de competição da tradicional arena legislativa para a arena judicial também. Pereira e Taylor (2010) atentam para o problema de incerteza que a lei pode causar, dadas as dificuldades no processamento das demandas - em 2010 foram mais de 200 recursos ao TSE de políticos que tiveram suas candidaturas impugnadas em outras instâncias. Destes recursos, o tribunal havia julgado 164 até o dia 13 dezembro de 2010, tendo acolhido mais de um terço e permitindo a esses políticos cassados tomarem posse. Apesar destes problemas, os autores concluem que a lei é positiva visto ter resultado da força da sociedade civil no sentido de reivindicar reformas para promover maior accountability, e no sentido de fortalecer as instituições de governança eleitoral.

Esta é a discussão corrente na academia, mas como este cenário foi percebido aos olhos do eleitor? Mais especificamente, nos interessa entender empiricamente se e como o eleitor percebe o papel do Poder Judiciário no processo eleitoral.

A informação do eleitor

Nesta seção, apresentamos dados e conclusões do survey. Em primeiro lugar, expomos como os eleitores informaram-se sobre as eleições, os temas relevantes, os meios de comunicação utilizados, a percepção da participação da justiça eleitoral e a aprovação ou não da lei da "ficha limpa". Ao analisarmos estes dados a partir das variáveis renda e escolaridade, fica evidente o papel determinante que a escolaridade tem neste processo.

Como o brasileiro acompanhou as eleições de 2010 e de que maneira se informou sobre elas? A grande maioria declarou ter acompanhado as eleições pelo noticiário na televisão (88\%), em

\footnotetext{
${ }^{4}$ No entanto, tal (in)decisão foi revista em março de 2011, com o voto do novo Ministro do Supremo, Luiz Fux. No dia 23/03/2011, durante julgamento de recurso extraordinário de Leonídio Bouças (PMDB), candidato a deputado estadual em Minas Gerais, Fux votou pela não aplicação da Lei da "ficha limpa" nas eleições de 2010.
} 
FALCÃO, J.; OLIVEIRA, F. L. Poder Judiciário e Competição Política: as eleições de 2010... conversas com familiares e conhecidos (86\%), e pela propaganda eleitoral gratuita (82\%). A ordem de importância destes canais para os eleitores é a mesma, independente de renda ou escolaridade.

A mídia impressa e o rádio vêm na sequência, atingindo respectivamente $52 \%$ e $45 \%$ dos eleitores. Já a internet aparece em último lugar, atingindo aproximadamente $36 \%$ dos eleitores ${ }^{5}$.

É notável que a televisão continua sendo a maior fonte de informação do eleitor, através de dois momentos televisivos radicalmente distintos: o noticiário (telejornais, programas próprios e debates) e a propaganda eleitoral gratuita. Ou seja, enquanto veículo de informação, a televisão atua: (a) como um ator político ativamente participante, formulador de conteúdo político, ao produzir, editar e veicular os telejornais, programas e os debates e (b) como um ator político retransmissor, ao apenas colocar no ar o conteúdo político produzido pelos candidatos e partidos políticos na propaganda eleitoral gratuita.

Tabela 1

Entrevistados que declararam ter acompanhado as últimas eleições que ocorreram em outubro de 2010, de acordo com renda e escolaridade (\%)

\begin{tabular}{|l|c|c|c|c|c|c|c|}
\cline { 3 - 8 } \multicolumn{1}{c|}{} & Total & \multicolumn{3}{c|}{ Renda } & \multicolumn{3}{c|}{ Escolaridade } \\
\cline { 3 - 8 } & $\begin{array}{c}\text { Baixa } \\
\text { (até 4 SM) }\end{array}$ & $\begin{array}{c}\text { Média } \\
(+4 \text { a 12SM) }\end{array}$ & $\begin{array}{c}\text { Alta } \\
(+12 S M)\end{array}$ & Baixa & Média & Alta \\
\hline Noticiário TV & 88 & 86 & 92 & 94 & 84 & 91 & 94 \\
\hline $\begin{array}{l}\text { Conversas com } \\
\text { amigos, familiares }\end{array}$ & 86 & 84 & 88 & 91 & 81 & 89 & 93 \\
\hline $\begin{array}{l}\text { Propaganda } \\
\text { eleitoral gratuita } \\
\text { (TV) }\end{array}$ & 82 & 84 & 82 & 87 & 83 & 83 & 78 \\
\hline Mídia impressa & 52 & 48 & 56 & 78 & 44 & 55 & 68 \\
\hline Rádio & 45 & 45 & 44 & 54 & 46 & 43 & 43 \\
\hline Internet & 36 & 26 & 50 & 57 & 18 & 46 & 65 \\
\hline
\end{tabular}

Fonte: Survey "Poder Judiciário e Eleições 2010".

Pergunta: "O(a) Sr(a) acompanhou as últimas eleições que ocorreram em outubro de 2010 pelo(a) ... sim ou não?

Esta dupla participação política da televisão, ambas extremamente relevantes para a informação do eleitor, explica a permanente preocupação dos congressistas em manter a propaganda eleitoral gratuita, que em muitos países inexiste, e de tentar estabelecer para o telenoticiário parâmetros legais viabilizadores da igualdade de oportunidades na competição político-eleitoral.

Os dados da pesquisa indicam que a grande maioria acompanhou de alguma forma as eleições. Mas o fato de ter acompanhado não implica que o brasileiro tenha se informado sobre o

\footnotetext{
${ }^{5} \mathrm{O}$ uso da internet para a busca de informação política varia de acordo com a escolaridade da população. Comparando acesso e uso, vemos que entre as pessoas com baixa escolaridade (até ensino fundamental), $45 \%$ têm acesso à internet, mas apenas $18 \%$ delas declararam utilizá.la para se informar sobre as eleições. Das pessoas com ensino médio, $71 \%$ têm acesso, mas apenas $46 \%$ utilizam a internet para fins de informação política e entre os com alta escolaridade, $93 \%$ têm acesso, mas apenas $65 \%$ utilizam com esta finalidade. Os dados de acesso são da pesquisa TIC Domicílios e Usuários de 2009, realizada pelo CETIC (http://www.cetic.br/usuarios/tic/2009/analises.htm). Acesso não significa posse no domicílio, mas sim utilização em qualquer lugar - seja em casa, em lan house, na escola, no trabalho, etc.
} 
OPINIÃO PÚBLICA, Campinas, vol. 18, n², novembro, 2012, p. 337-354

envolvimento do Poder Judiciário. Os meios de comunicação, por exemplo, deram grande destaque à polêmica em torno do aborto e do episódio da lei da "ficha limpa", mas ambos os temas apareceram pouco como fatos marcantes e relevantes para os eleitores. Não houve grande envolvimento da população com os temas debatidos.

Ao serem indagados sobre notícia ou fato marcante durante as eleições, pouco mais da metade soube responder (54\% dos entrevistados). Houve uma pulverização de temas: a disputa entre os dois candidatos mais fortes, Dilma e Serra, e a troca de agressões foi o fato mais citado, com $14 \%$ das menções. O segundo tema, a corrupção, apareceu com $8 \%$. Em terceiro lugar, com $5 \%$ das menções e com referências pouco específicas, aparecem as propostas de candidatos. Em quarto, com $4 \%$ de citações, está o aborto. Ao contrário dos Estados Unidos, onde a questão do aborto é um tema importante, sobretudo um indicador da opção religiosa no debate, nas eleições brasileiras de 2010 o tema não motivou os eleitores, apesar de sua grande repercussão midiática. Tão pouco a lei da "ficha limpa", que foi citada espontaneamente por apenas $1 \%$ dos entrevistados.

É importante notar que o episódio da "ficha limpa" não foi fato corriqueiro no exercício da competência regulatória e jurisdicional da justiça eleitoral. Foi um acontecimento político que mereceu ampla cobertura dos telejornais, sites e blogs, sendo as sessões do Supremo transmitidas em tempo real. Os dados do survey permitem inferir desde logo o limitado impacto que a transmissão ao vivo das sessões do Supremo têm diretamente sobre o eleitor, inferência a ser confirmada por pesquisas posteriores, seja em decorrência da mínima audiência da TV Justiça seja pelo mínimo impacto multiplicador que a transmissão possa ter tido via outras redes de televisão e internet, como fornecedor de informação televisada ${ }^{6}$. 0 impacto é na elite política.

As menções às notícias de maior destaque variam, no entanto, de acordo com a renda e a escolaridade dos entrevistados - quanto maior a renda e a escolaridade, maior a proporção dos entrevistados que citou alguma notícia marcante. As agressões trocadas entre Dilma e Serra foram mencionadas por $27 \%$ dos entrevistados de renda alta e pelos com alta escolaridade, contra apenas $11 \%$ dos entrevistados de renda baixa e $10 \%$ dos de escolaridade baixa. E o tema da corrupção aparece entre $13 \%$ dos de renda mais alta e $15 \%$ dos de escolaridade alta, contra $5 \%$ da população de baixa renda e $6 \%$ dos com baixa escolaridade. Nem escolaridade nem renda dos entrevistados impactaram na menção do caso "ficha limpa".

\footnotetext{
${ }^{6}$ Futuros estudos sobre o impacto da transmissão ao vivo das sessões do Supremo e do CNJ sobre o cidadão, enquanto partes judiciais e eleitor, poderão contribuir para a avaliação do princípio da transparência decisória na teoria da democracia.
} 
FALCÃO, J.; OLIVEIRA, F. L. Poder Judiciário e Competição Política: as eleições de 2010...

Tabela 2

Fatos e notícias mais marcantes nas eleições de 2010 (\%)

\begin{tabular}{|c|c|c|c|c|c|c|c|}
\hline & & & Renda & & & scolaric & \\
\hline & Total & $\begin{array}{c}\text { Baixa } \\
\text { (até } 4 \mathrm{SM} \text { ) }\end{array}$ & $\begin{array}{c}\text { Média } \\
(+4 \text { a } \\
12 S M)\end{array}$ & $\begin{array}{c}\text { Alta } \\
(+12 S M)\end{array}$ & Baixa & Média & Alta \\
\hline $\begin{array}{l}\text { Agressões entre Dilma e } \\
\text { Serra }\end{array}$ & 14 & 11 & 17 & 27 & 10 & 14 & 26 \\
\hline Corrupção dos candidatos & 8 & 5 & 10 & 13 & 6 & 7 & 15 \\
\hline Propostas dos candidatos & 5 & 5 & 6 & 1 & 5 & 5 & 5 \\
\hline Aborto & 4 & 4 & 4 & 6 & 2 & 6 & 2 \\
\hline A polêmica sobre Tiririca & 3 & 2 & 3 & 3 & 2 & 3 & 6 \\
\hline A vitória de Dilma & 2 & 2 & 2 & 1 & 2 & 3 & 1 \\
\hline O caso de Erenice Guerra & 2 & 2 & 2 & 3 & 1 & 3 & 4 \\
\hline As propostas de Dilma & 2 & 3 & 1 & 0 & 3 & 1 & 0 \\
\hline $\begin{array}{l}\text { A lei da "ficha limpa"/ os } \\
\text { "fichas suja" }\end{array}$ & 1 & 1 & 2 & 1 & 1 & 2 & 2 \\
\hline Outras & 13 & 12 & 17 & 18 & 12 & 14 & 16 \\
\hline $\begin{array}{l}\text { Nenhuma/ Não soube } \\
\text { responder }\end{array}$ & 46 & 52 & 37 & 25 & 56 & 43 & 25 \\
\hline
\end{tabular}

Fonte: Survey "Poder Judiciário e Eleições 2010".

Pergunta: "Nestas eleições, qual foi a notícia ou fato que mais chamou a atenção do(a) Sr(a)?"

Perguntamos, então, diretamente sobre o envolvimento do Poder Judiciário nas eleições. A maioria dos brasileiros não acompanhou sua participação nas eleições de 2010 - apenas 19\% afirmaram ter acompanhado ou ouvido falar algo sobre a participação do Judiciário (ou dos juízes) nas últimas eleições.

E o que influencia e determina o conhecimento dos brasileiros acerca do envolvimento do Poder Judiciário nas eleições? Conforme os dados da Tabela 3, vemos que quanto maior a escolaridade e a renda do eleitor, maior o conhecimento do envolvimento do Judiciário nas eleições - enquanto apenas $14 \%$ dos que têm baixa renda tiveram conhecimento desta participação, $21 \%$ dos de renda média e $49 \%$ dos de renda alta o tiveram. Em termos de escolaridade, tal conhecimento foi de $12 \%$ entre os de baixa escolaridade, $19 \%$ entre os de média escolaridade e $37 \%$ entre os de alta escolaridade.

Tabela 3

Entrevistados que declararam saber algo sobre a participação do Judiciário (ou juízes) nas eleições que ocorreram em outubro de 2010 (\%)

\begin{tabular}{|c|c|c|c|c|c|c|c|c|c|c|c|c|}
\hline \multirow[b]{2}{*}{ Total } & \multicolumn{3}{|c|}{ Renda } & \multicolumn{3}{|c|}{ Escolaridade } & \multicolumn{2}{|c|}{$\begin{array}{c}\text { Experiênci } \\
\text { a prévia } \\
\text { Judiciário }\end{array}$} & \multicolumn{4}{|c|}{ Conhecimento do Judiciário } \\
\hline & $\begin{array}{c}\text { Baixa } \\
\text { (até } \\
4 \text { SM) }\end{array}$ & $\begin{array}{c}\text { Média } \\
(+4 \text { a } \\
12 S M)\end{array}$ & $\begin{array}{c}\text { Alta } \\
(+12 \mathrm{SM})\end{array}$ & Baixa & Média & Alta & Sim & Não & $\begin{array}{c}\text { Não } \\
\text { conhece }\end{array}$ & $\begin{array}{l}\text { Conhece } \\
\text { só de } \\
\text { ouvir } \\
\text { falar }\end{array}$ & $\begin{array}{c}\text { Conhece } \\
\text { um } \\
\text { pouco }\end{array}$ & $\begin{array}{l}\text { Conhe } \\
\text { ce } \\
\text { muito }\end{array}$ \\
\hline 19 & 14 & 21 & 49 & 12 & 19 & 37 & 24 & 17 & 10 & 11 & 22 & 34 \\
\hline
\end{tabular}

Fonte: Survey "Poder Judiciário e Eleições 2010".

Pergunta: "O(a) Sr(a) sabe ou ouviu falar algo sobre a participação do Judiciário (ou juízes) nestas eleições? 
OPINIÃO PÚBLICA, Campinas, vol. 18, n², novembro, 2012, p. 337-354

O mesmo se aplica para o nível de conhecimento do Judiciário, quanto mais o eleitor conhece o Poder Judiciário, mais conhece o envolvimento dele nas eleições de 2010. E aqueles que já utilizaram o serviço do Judiciário, ou seja, os que já entraram com uma ação no Judiciário, também tendem a acompanhar mais sua atuação no cenário eleitoral.

Consideramos que têm experiência prévia com o Judiciário aqueles que declararam que já entraram com uma ação no Judiciário (pessoalmente ou alguém residente no mesmo domicílio), seja juizados especiais, justiça comum, do trabalho, etc. Foram 30\% dos entrevistados que declararam já ter utilizado o Poder Judiciário, sendo que quanto maior a escolaridade, maior o uso.

$\mathrm{E}$, no que se refere ao nível de conhecimento, há uma questão no survey em que se pergunta ao entrevistado o quanto ele diria que conhece ou sabe sobre o Poder Judiciário, sendo as respostas possíveis: "não conhece nada"; "conhece só de ouvir falar"; "conhece mais ou menos bem" ou "conhece muito bem". 59\% declararam "conhecer mais ou menos bem" ou "muito bem". Novamente, quanto maior a escolaridade, maior o conhecimento declarado.

Tabela 4

Experiência prévia com Judiciário e familiaridade, por escolaridade (\%)

\begin{tabular}{|l|c|c|c|c|}
\hline \multirow{2}{*}{} & \multirow{2}{*}{ Total } & \multicolumn{3}{|c|}{ Escolaridade } \\
\cline { 3 - 5 } & & Baixa & Média & Alta \\
\hline Têm experiência prévia Judiciário & 30 & 23 & 32 & 45 \\
\hline & & & & \\
\hline Familiaridade com Poder Judiciário & & 29 & 14 & 5 \\
\hline Não conhece & 19 & 26 & 23 & 12 \\
\hline Conhece só de ouvir falar & 22 & 38 & 51 & 54 \\
\hline Conhece mais ou menos bem & 46 & & & 29 \\
\hline Conhece muito bem & & 7 & 13 & 29 \\
\hline
\end{tabular}

Fonte: Survey "Poder Judiciário e Eleições 2010"

Perguntas: 1) Gostaria de saber se O Sr(a) ou alguém do seu domicilio já utilizou o Judiciário, ou seja, já entrou com algum processo ou ação na justiça? E 2) O sr(a) diria que conhece muito bem, conhece mais ou menos bem,

conhece só de ouvir falar, ou não conhece o funcionamento do Judiciário, ou seja o funcionamento da Justiça?

Aos que declararam saber algo sobre a participação do Judiciário nas eleições de 2010, perguntamos sobre o conteúdo do que sabiam sobre essa participação. Cerca de $32 \%$ não souberam responder, donde se conclui que, efetivamente, apenas $13 \%$ da população atentou para a participação do Judiciário nas eleições de 2010.

Entre que souberam relatar algo, o assunto mais citado foi a lei da "ficha limpa", mencionada por $44 \%$ dos entrevistados. Na sequência, apareceram a fiscalização da boca de urna (8\%), a organização geral das eleições (7\%), o combate à corrupção e fraudes eleitorais (2\%), etc. 
FALCÃO, J.; OLIVEIRA, F. L. Poder Judiciário e Competição Política: as eleições de 2010...

É neste cenário de desconhecimento que situa-se o episódio da "ficha limpa". Parece existir uma desproporção entre o impacto que a decisão do Supremo teve na modelagem legal da competição política em 2010 - uma decisão que atingiu potencialmente o destino de milhares de candidatos e milhões de votos - e a ausência de percepção do eleitor sobre este impacto. Não se trata de perceber a participação do Poder Judiciário positiva ou negativamente. Trata-se simplesmente de pouco ou nada perceber.

Uma possível explicação para esta "não percepção" seria o fato de que o eleitor não é participante direto da litigância eleitoral. São os candidatos e os partidos, em geral, as partes judiciais. O eleitor não é usuário direto dos serviços da justiça eleitoral - o ator político relevante para o serviço de adjudicação são os partidos políticos e os candidatos.

Porém, como veremos adiante, o eleitor avalia positivamente a atuação da justiça eleitoral na organização e realização das eleições. Confia, inclusive, em sua atuação fiscalizadora. A hipótese que podemos esboçar é de que a confiança do eleitor na justiça eleitoral é o resultado da não percepção de sua competência regulatória e jurisdicional e da percepção positiva de sua competência como organizadora e realizadora das eleições. Praticamente inexiste a necessidade de o eleitor procurar a justiça eleitoral para dirimir conflitos em que esteja diretamente envolvido. Para o eleitor, o que contaria seria a eficiência da gestão das eleições propriamente ditas que, desde 1988, têm ocorrido dentro de uma normalidade democrática acima da média inclusive de países mais desenvolvidos ${ }^{7}$.

Entre os que acompanharam o envolvimento do Poder Judiciário nestas eleições, a avaliação de seu desempenho foi positiva, com $68 \%$ afirmando que o Judiciário teve uma atuação ótima ou boa. Ainda, esta atuação foi percebida como melhor entre os eleitores de maior escolaridade, e também entre os que já tiveram experiência prévia com o Judiciário.

Tabela 5

Entrevistados que avaliaram como ótima ou boa a atuação da Justiça Eleitoral nas eleições que ocorreram em outubro de 2010 (\%)

\begin{tabular}{|c|c|c|c|c|c|c|c|c|c|c|c|}
\hline Total & \multicolumn{3}{|c|}{ Renda } & \multicolumn{3}{c|}{ Escolaridade } & $\begin{array}{c}\text { Experiênci } \\
\text { a prévia } \\
\text { Judiciário }\end{array}$ & \multicolumn{3}{c|}{ Conhecimento do Judiciário } \\
\hline & $\begin{array}{c}\text { Baixa } \\
\text { (até 4 } \\
\text { SM) }\end{array}$ & $\begin{array}{c}\text { Média } \\
(+4 a \\
12 S M)\end{array}$ & $\begin{array}{c}\text { Alta } \\
(+12 S M)\end{array}$ & Baixa & Média & Alta & Sim & Não & $\begin{array}{c}\text { Não } \\
\text { conhece }\end{array}$ & $\begin{array}{c}\text { Conhece só } \\
\text { de ouvir } \\
\text { falar }\end{array}$ & $\begin{array}{c}\text { Conhece } \\
\text { um } \\
\text { pouco } \\
\text { Conhece } \\
\text { muito }\end{array}$ \\
\hline 68 & 69 & 74 & 50 & 59 & 72 & 71 & 74 & 64 & 69 & 56 & 71 \\
\hline
\end{tabular}

Fonte: Survey "Poder Judiciário e Eleições 2010".

Base: 241 entrevistas (que declararam saber algo da participação do Judiciário nas eleições). Pergunta: E como o(a) Sr(a) avalia a atuação especificamente da Justiça eleitoral nas eleições deste ano, o(a) Sr(a) acha foi ótima, boa, regular, ruim, ou péssima?

\footnotetext{
7 É por isso que a justiça eleitoral é sempre uma das justiças mais bem avaliadas, assim como a justiça trabalhista. Cada uma, e esta é uma hipótese para ser testada em pesquisas futuras, por motivos distintos. A justiça trabalhista por que o brasileiro nela encontra a sua defensora, por isto confia nela. A justiça eleitoral por que ela é eficiente na gestão das eleições.
} 
A lei de "ficha limpa"

Não obstante a baixa percepção da questão do debate sobre a "ficha limpa" durante a campanha eleitoral, a maioria dos brasileiros declarou conhecer ou ter ouvido falar sobre a lei da "ficha limpa" (85\% da população). Desse total que disse conhecer a lei, a maioria (73\%) soube definir seu conteúdo, ou seja, aproximadamente $60 \%$ do eleitorado brasileiro conhece efetivamente a lei da "ficha limpa".

Como esperado, quanto maiores a escolaridade e a renda, maior o conhecimento da lei e do seu conteúdo. E entre os que souberam definir o que é a lei, $73 \%$ declararam tê-la levado em consideração na hora da escolha do voto - ou seja, aproximadamente $44 \%$ do eleitorado considerou se o candidato escolhido era ou não "ficha limpa" na hora de votar".

Depois de mensurar o quanto e o quê a população sabe sobre a lei da "ficha limpa", foi apresentado a todos, de forma bastante simples, o que é a lei: "pela lei da ficha limpa, políticos condenados pela Justiça, ainda que provisoriamente, não poderiam concorrer às eleições e assumir cargos eletivos".

A grande maioria dos brasileiros (87\%) aprova a lei e concorda que ela deveria valer já para as eleições de $2010^{9}$. Novamente, a escolaridade influencia a percepção - quanto maior o grau de instrução, maior a concordância com os benefícios da lei e com sua validade imediata.

Apesar de a maioria conhecer a lei da "ficha limpa", somente uma minoria (24\%) declarou saber algo sobre a participação do Judiciário no caso. O conhecimento e a percepção favorável da Lei da "ficha limpa" precedem o dia das eleições - como indica a pesquisa da AMB (Associação da Magistratura Brasileira) realizada em agosto de $2010^{10}$. Em relação ao que sabem sobre a participação do Judiciário no caso, o fato mais citado foi a cassação de candidatos "ficha suja" pelo Judiciário (33\%). Apenas 6\% mencionaram a divisão de votos no Supremo sobre a validade ou não da lei para as eleições de 2010 . Ou seja, menos de $2 \%$ do total dos eleitores.

E quais são os fatores que explicam esse, ainda que insuficiente, conhecimento? Para responder a esse questionamento utilizamos um modelo de regressão logística.

\footnotetext{
8 É esperado que declarem levar em conta a lei na hora de votar. Curioso é que $66 \%$ dos entrevistados disseram não conhecer candidato ou político "ficha suja" ao serem indagados sobre um nome. Mas, quanto maior a escolaridade, maior o conhecimento - 75\% dos entrevistados com escolaridade baixa declararam não conhecer político "ficha suja", contra 48\% das pessoas com escolaridade alta. Entre os que disseram conhecer político "ficha suja" o nome mais citado foi o de Paulo Maluf, com $9 \%$ das menções. Na sequência, os mais citados foram Jader Barbalho (com 5\% das menções), Roriz (com 3\%) e Dilma (com 2\%). Sendo que Zé Dirceu, Collor, Garotinho, Serra e Sarney aparecem cada um com 1\% de citações.

9 A disputa entre as duas possibilidades que resumem o debate acerca da lei da "ficha limpa" que acabou levando ao seu julgamento pelo Judiciário foi apresentada aos entrevistados de forma bastante simples. Os argumentos foram formulados da seguinte forma: "Algumas pessoas acham justo a lei da "ficha limpa" valer para estas eleições que ocorreram agora, já que foi aprovada antes dos partidos escolherem seus candidatos. Outros acham que o mais justo seria a lei valer apenas nas próximas eleições, já que a maioria das leis eleitorais só vale para o ano seguinte a sua aprovação. Com qual posição o(a) Sr(a) concorda mais: a Lei da "ficha limpa" valer para as eleições que ocorreram esse ano ou apenas para as próximas eleições?".

10 Segundo a pesquisa, $85 \%$ dos eleitores eram favoráveis a Lei da "ficha limpa", $9 \%$ não conheciam e $3 \%$ se declararam contrários. A pesquisa aponta ainda que $91 \%$ da população declararam considerar importante a participação de entidades de juízes em campanhas contra a corrupção eleitoral.
} 
FALCÃO, J.; OLIVEIRA, F. L. Poder Judiciário e Competição Política: as eleições de 2010...

Tabela 6

Regressão logística, considerando como variável alvo o conhecimento sobre envolvimento do Poder Judiciário na decisão sobre a lei da "ficha limpa"

\begin{tabular}{|l|c|c|}
\cline { 2 - 3 } \multicolumn{1}{c|}{} & \multicolumn{1}{c|}{ Coeficiente B } & Exponencial das Chances \\
\hline Escolaridade Alta & Referência & 0,609 \\
\hline Escolaridade Média & $-0,495^{*}$ & 0,567 \\
\hline Escolaridade Baixa & $-0,567^{*}$ & 0,809 \\
\hline Renda Alta & Referência & 0,783 \\
\hline Renda Média & $-0,212$ & 1,689 \\
\hline Renda Baixa & $-0,244$ & 1,419 \\
\hline $\begin{array}{l}\text { Nível de Conhecimento sobre o } \\
\text { PJ }\end{array}$ & $0,524^{* *}$ & 1,332 \\
\hline Gênero (feminino) & $0,350^{*}$ & 0,193 \\
\hline Experiência Prévia com PJ & $0,286^{*}$ & \\
\hline & & \\
Constante & $-1,645^{* *}$ & \\
\hline
\end{tabular}

**significativo ao nível 0,01 *significativo ao nível 0,05.

Nagelkerke R Square = 0,114 (na classificação do modelo, entre observado e predito, o modelo acerta em $77 \%$ dos casos, o que indica um bom desempenho). Número de observações: 1.300 .

O modelo indica que quanto menor a escolaridade, menores as chances de conhecimento do envolvimento do Judiciário no caso, sendo que a renda aqui não é significativa. 0 nível de conhecimento do Judiciário também influi no conhecimento de seu acompanhamento no caso "ficha limpa" - quanto maior a familiaridade e o conhecimento da instituição, maiores as chances de conhecer e acompanhar a discussão da "ficha limpa" no Judiciário. E as chances de conhecimento do envolvimento do Judiciário nesse caso também são maiores entre os que já tiveram experiência prévia com o Judiciário, comparados aos que não tiveram tal experiência. Os que tiveram experiência anterior com o Judiciário têm 33\% a mais de chances de conhecer o envolvimento do Judiciário no caso "ficha limpa", comparados aos que não tiveram experiência anterior com o Judiciário. Ou seja, mesmo controlando e isolando os efeitos de renda e escolaridade, a experiência prévia com o Judiciário permanece significativa.

Por fim, foi apresentada aos entrevistados a decisão do Supremo Tribunal Federal do dia 27 de outubro de 2010, que "decidiu que a Lei da ficha limpa valeu nas eleições de 2010, e os candidatos ficha suja que foram eleitos devem perder os cargos. O(a) Sr(a) acha certa ou errada essa decisão?". E a grande maioria avaliou como correta (91\%). Quanto maiores a escolaridade e a renda, maior a concordância com o Supremo. A concordância também é maior entre aqueles com experiência prévia na justiça.

Os dados até aqui analisados indicam que a informação do eleitor sobre a participação do Poder Judiciário no processo eleitoral é baixa, assim como sobre a participação da instituição no debate e decisão sobre a validade da "ficha limpa". No entanto, este eleitor apoia a atuação da justiça eleitoral, e é favorável à lei "ficha limpa". E apoia a validade imediata da lei, mesmo sem estar informado diretamente sobre a decisão do Supremo. 
OPINIÃO PÚBLICA, Campinas, vol. 18, n², novembro, 2012, p. 337-354

Se retomarmos a distinção de Easton sobre os apoios difuso e específico ao Poder Judiciário, e se considerarmos este apoio difuso fonte da reserva de legitimidade decorrente da atuação inespecífica do Poder Judiciário, podemos concluir que a decisão do Supremo, ainda que não conhecida diretamente pelo eleitor, acumulou junto a este mesmo eleitor um capital de legitimidade a contra senso. O eleitor é favorável à lei, independentemente da posição do Supremo. Mas, se o Supremo não tivesse validado a lei, provavelmente, aí sim, o eleitor estaria mais informado e desaprovaria a justiça eleitoral. A indireta e provisória decisão do Supremo validando a lei garantiu, naquele momento, o capital de legitimidade da justiça eleitoral como participante do processo de governança da competição política junto ao eleitor.

A percepção das distintas competências

Dentro da diferenciação entre as três competências - administrativa, regulatória e jurisdicional-, perguntamos à população sua visão sobre quem deveria ser o responsável por organizar e fiscalizar o processo eleitoral e garantir sua lisura. A maioria dos brasileiros aponta o Ministério Público em primeiro lugar e o Poder Judiciário em segundo. E note-se que, quanto maiores a renda e a escolaridade, maior a importância dada a estas instituições. O Judiciário é citado por $44 \%$ dos entrevistados com experiência prévia na justiça.

Em terceiro lugar aparecem os próprios eleitores. Como demonstrado por estudos de comportamento político recentes, o eleitor é defensor da transparência política, mas tende a não querer participar ativamente do processo político ${ }^{11}$. Quanto maior a renda, maior a propensão do brasileiro declarar o eleitor como principal fiscalizador das eleições. E o contrário para o Presidente da República.

Tabela 7

Principal instituição responsável pela organização e fiscalização do processo eleitoral (\%)

\begin{tabular}{|c|c|c|c|c|c|c|c|c|c|}
\hline & \multirow{2}{*}{ TOTAL } & \multicolumn{3}{|c|}{ Renda } & \multicolumn{3}{|c|}{ Escolaridade } & \multicolumn{2}{|c|}{$\begin{array}{c}\text { Experiência } \\
\text { prévia } \\
\text { Judiciário }\end{array}$} \\
\hline & & $\begin{array}{c}\text { Baixa } \\
\text { (até } 4 \\
\text { SM) }\end{array}$ & $\begin{array}{c}\text { Média } \\
(+4 \text { a } 12 \\
\text { SM })\end{array}$ & $\begin{array}{l}\text { Alta } \\
(+12 \\
\text { SM }) \\
\end{array}$ & Baixa & Média & Alta & Não & Sim \\
\hline Ministério Público & 40 & 35 & 55 & 59 & 29 & 45 & 61 & 43 & 51 \\
\hline Poder Judiciário & 31 & 28 & 37 & 41 & 27 & 33 & 36 & 31 & 44 \\
\hline Eleitores & 27 & 24 & 31 & 41 & 21 & 33 & 27 & 28 & 32 \\
\hline $\begin{array}{l}\text { Presidente da } \\
\text { República }\end{array}$ & 20 & 24 & 9 & 19 & 28 & 15 & 9 & 25 & 16 \\
\hline Polícia & 17 & 20 & 9 & 10 & 21 & 14 & 9 & 21 & 15 \\
\hline Partidos políticos & 13 & 15 & 12 & 0 & 16 & 11 & 10 & 15 & 12 \\
\hline Congresso Nacional & 8 & 8 & 8 & 12 & 9 & 6 & 8 & 10 & 8 \\
\hline Mídia & 6 & 5 & 13 & 10 & 5 & 7 & 9 & 7 & 9 \\
\hline ONGs & 3 & 3 & 3 & 7 & 2 & 3 & 4 & 3 & 4 \\
\hline Não sabe (Espontâneo) & 13 & 14 & 6 & 0 & 17 & 9 & 9 & 16 & 10 \\
\hline
\end{tabular}

Fonte: Survey "Poder Judiciário e Eleições 2010". Base: 1.300 entrevistas.

Pergunta: "Na sua opinião, quem deveria ser o principal responsável por organizar e fiscalizar as eleições no país? E em segundo lugar?"

11 Ver Oliveira, Luci e Page, Ben (2008). 
FALCÃO, J.; OLIVEIRA, F. L. Poder Judiciário e Competição Política: as eleições de 2010...

Quanto menor a renda do respondente, maior a propensão de citar o Presidente como o principal fiscalizador das eleições. Como, em outubro de 2010, Lula apresentava um índice de aprovação de cerca de $80 \%$, é importante ressaltar o peso que o "fenômeno Lula" tem para esse prestígio do Presidente como fiscal do processo eleitoral.

Esta é a visão espontânea do papel do Judiciário na organização e fiscalização do processo eleitoral. Mas, o que acontece quando estimulamos os eleitores a pensarem no papel do Judiciário na sua relação com os outros Poderes e com a efetividade das regras do processo eleitoral?

Para isso, mensuramos primeiro o apoio difuso, ou seja, o apoio relativo ao papel da instituição, sem tocar diretamente em seu desempenho: importância do Judiciário na organização e fiscalização do processo eleitoral como um todo e no combate à corrupção neste processo.

Apesar de ter pouco conhecimento sobre a atuação específica do Poder Judiciário nas eleições de 2010 e no caso "ficha limpa", o eleitor tem uma atitude extremamente positiva quanto à atuação do Poder Judiciário Eleitoral como garantidor da lisura do processo eleitoral (apoio difuso). A vasta maioria dos entrevistados avaliou como "importante" ou "muito importante" o seu na organização e fiscalização das eleições e no combate à corrupção (91\% em ambos os casos). Ou seja, o Judiciário goza de respaldo e apoio popular para desempenhar esta competência. Competência esta decisiva que distingue a governança eleitoral do Brasil da dos demais países. E, como o Poder Judiciário Eleitoral a tem exercido?

Mensuramos então a percepção sobre a honestidade e independência do Judiciário para exercer tal competência. Nestas dimensões, há um pouco mais de desconfiança, com $46 \%$ acreditando que o Judiciário é "independente" - 33\% afirmando que é "pouco independente" e para 9\% o Judiciário é "nada independente" - $13 \%$ não souberam opinar. Na dimensão da honestidade, os percentuais foram de $44 \%$ afirmando ser o Judiciário “honesto na fiscalização das eleições”, 33\% "pouco honesto", 10\% "nada honesto" e $14 \%$ não souberam opinar.

Com base nestas quatro dimensões, construímos um indicador de percepção do papel do Judiciário no processo eleitoral. Esse indicador é um proxy da credibilidade do Judiciário como fiscalizador e organizador do processo eleitoral, variando de 0 a 1 - quanto mais próximo de 1 mais positiva é a percepção e maior a credibilidade do Judiciário e quanto mais próximo de 0 , mais negativa e menor a credibilidade. 


\section{Tabela 8}

\section{Indicador de Percepção do Papel do Judiciário no Processo Eleitoral (média)}

\begin{tabular}{|c|c|c|c|c|c|c|c|c|c|c|c|c|}
\hline \multirow{2}{*}{ TOTAL } & \multicolumn{3}{|c|}{ Renda } & \multicolumn{3}{|c|}{ Escolaridade } & \multicolumn{2}{|c|}{$\begin{array}{c}\text { Experiência } \\
\text { Prévia } \\
\text { Judiciário }\end{array}$} & \multicolumn{4}{|c|}{ Conhecimento do Judiciário } \\
\hline & $\begin{array}{c}\text { Baixa } \\
\text { (até } 4 \mathrm{SM} \text { ) }\end{array}$ & $\begin{array}{c}\text { Média } \\
(+4 \text { a } 12 S M)\end{array}$ & $\begin{array}{c}\text { Alta } \\
(+12 S M)\end{array}$ & Baixa & Média & Alta & Sim & Não & $\begin{array}{c}\text { Não } \\
\text { conhece }\end{array}$ & $\begin{array}{c}\text { Conhece só de } \\
\text { ouvir falar }\end{array}$ & $\begin{array}{l}\text { Conhece } \\
\text { um pouco }\end{array}$ & $\begin{array}{c}\text { Conhece } \\
\text { muito }\end{array}$ \\
\hline 0,58 & 0,57 & 0,61 & 0,61 & 0,56 & 0,59 & 0,61 & 0,60 & 0,58 & 0,52 & 0,56 & 0,60 & 0,61 \\
\hline
\end{tabular}

Fonte: Survey "Poder Judiciário e Eleições 2010". Base: 1.300 entrevistas.

Perguntas: 1) Na sua opinião, qual a importância do Judiciário na fiscalização das eleições. O(a) Sr(a) diria que o Judiciário é nada importante, pouco importante, importante ou muito importante no processo de fiscalização das eleições? 2) Na sua opinião, qual a importância do Judiciário no combate à corrupção nas eleições. $\mathrm{O}$ (a) Sr(a) diria que o Judiciário é nada importante, pouco importante, importante ou muito importante? 3) E quanto à honestidade do Judiciário (ou seja, a capacidade de resistir a subornos), para o Sr(a) o Judiciário na fiscalização das eleições é muito honesto, honesto, pouco honesto ou nada honesto? e 4) E quanto à independência do Judiciário, ou seja, sua capacidade de resistir a pressões e influência dos políticos, o(a) Sr(a) diria que o Judiciário na fiscalização das eleições é muito independente, independente, pouco independente ou nada independente?

A percepção do papel do Judiciário no processo eleitoral é positiva, e aumenta com o aumento da renda e da escolaridade. Caldeira e Gibson (1992) afirmam que a experiência com o Judiciário e seu conhecimento são fatores que contribuem para aumentar a credibilidade da instituição - em nossa pesquisa, verificamos que quanto maior o conhecimento declarado em relação a esse Poder, melhor a sua percepção. O mesmo verificou-se entre os que têm experiência com a justiça: eles apresentam uma visão mais positiva em comparação aos que nunca utilizaram o Judiciário.

De maneira geral, os dados do survey demonstram que o Judiciário goza de considerável respaldo popular para exercer a competência de organização e fiscalização do processo eleitoral.

\section{Conclusão}

Os dados analisados indicam uma percepção positiva do brasileiro sobre o papel do Poder Judiciário, mais especificamente da justiça eleitoral, no processo político eleitoral e demonstram que ela goza de legitimidade para a competência de organizar e fiscalizar a competição política. Neste sentido, quando se trata de governança eleitoral, o brasileiro confia nas instituições da justiça e reconhece a legitimidade do Poder Judiciário.

Porém, quando se trata da confiança específica na justiça eleitoral, ou seja, da avaliação do seu desempenho em uma situação concreta, os brasileiros desconhecem ou não deram importância à atuação do Judiciário nas eleições de 2010; nem mesmo ao episódio da lei da "ficha limpa" e ao conflito de sua validade que chegou ao Supremo e foi objeto de ampla repercussão na mídia no cenário eleitoral.

A percepção da importância do Judiciário está diretamente relacionada com a renda e a escolaridade do eleitorado (quanto maiores a escolaridade e a renda, maior a legitimidade dada a esta função). Aliás, antes disso, é fundamental considerar que o próprio conhecimento e o acesso ao Poder Judiciário são fortemente determinados pela renda e pela escolaridade da população ${ }^{12}$.

12 O suplemento "Vitimização e Justiça" da PNAD (2010) indica que quanto maiores a renda e a escolaridade, maior o acesso das pessoas ao Judiciário, que assim participa de suas vidas não apenas como Poder de Estado mas também como serviço 352 
FALCÃO, J.; OLIVEIRA, F. L. Poder Judiciário e Competição Política: as eleições de 2010...

Outras duas variáveis importantes na explicação da visão positiva da participação do Judiciário no processo eleitoral são a familiaridade e a experiência prévia com o Judiciário como equacionador de litígios.

Nossa conclusão sobre a confiabilidade no Judiciário Eleitoral não é contraditória às conclusões de estudos correntes sobre a desconfiança nas instituições políticas em geral e a baixa confiabilidade no Poder Judiciário (MoISÉs, 2005; MoISÉs e CARNEIRO, 2008; CunHA et al, 2010 ; FALCÃO, 2010). O fato de confiar no Judiciário como organizador e fiscalizador das eleições e, em contrapartida, não confiar no Judiciário como prestador de um serviço público jurisdicional ao cidadão comum é um indício de que os brasileiros de alguma forma percebem as múltiplas competências do Judiciário e as diversas justiças. É essencial, pois, aos estudos de confiança institucional levar em consideração, quando tratam do Poder Judiciário, as diferentes justiças e as diferentes funções e competências que elas exercem: jurisdicional, regulatória e administrativa.

Os brasileiros confiam e dão credibilidade ao papel desempenhado pelo Poder Judiciário no processo eleitoral, mas não o acompanham de fato. Apenas uma minoria percebeu o envolvimento do Judiciário nas eleições de 2010. Nem mesmo o episódio da lei da "ficha limpa" chamou a atenção dos eleitores para a importância e a centralidade do Poder Judiciário nas eleições - o que pode ser reflexo da baixa politização e da baixa escolaridade do eleitorado.

Na medida em que em todas as pesquisas de opinião, realizadas antes e depois das eleições, o eleitor afirmava-se favorável à "ficha limpa", o Supremo possivelmente capitalizou para a justiça eleitoral em específico, e para o Poder Judiciário em geral, um apoio difuso e acumulou maior legitimidade política diante do eleitor para participar do processo de governança política democrática. Resta saber agora, depois da decisão de março de 2011, se tal legitimidade sofrerá algum tipo de abalo e se a maioria dos eleitores continuará ainda a ignorar a atuação do STF ${ }^{13}$.

Mas, independente de acompanhar o desempenho efetivo do papel do Judiciário nas eleições, é fato que a justiça eleitoral, vista como singularidade jurídica e institucional brasileira, goza do respaldo do eleitor.

público. Pesquisa do IPEA, também divulgada em 2010, indica que o acesso ao Judiciário está diretamente relacionado ao níve de educação e de renda da população. Segundo o estudo, $63,85 \%$ de todas as demandas podem ser explicadas por níveis de educação e renda, sendo que o aumento de um ano na escolaridade média da população aumentaria a demanda por serviços judiciais em 1.682 casos novos por ano para cada 100 mil habitantes. E a redução de 1 ponto no percentual na pobreza aumentaria a demanda por serviços judiciais em 59 casos novos por ano para cada 100 mil habitantes. Disponível em:<http://www.ipea.gov.br/portal/index.php?option=com_content\&view=article\&id=6141\&ltemid=2v>.Também a pesquisa Índice de Confiança na Justiça (CuNHA et al, 2010) aponta essa relação entre o uso do Poder Judiciário, renda e educação enquanto apenas 34\% das pessoas de baixa renda já utilizaram os tribunais, $53 \%$ das pessoas com alta renda utilizaram. Entre as pessoas com baixa escolaridade $35 \%$ já utilizaram o Judiciário contra $61 \%$ da população com alta escolaridade.

$13 \mathrm{O}$ conhecimento que o brasileiro tem da atuação do Supremo Tribunal Federal é baixo. Survey nacional realizado pela FGV Direito Rio em fevereiro de 2011 indicou que 69\% dos brasileiros declararam conhecer o Supremo Tribunal Federal. Deste percentual que declarou conhecer, apenas $45 \%$ conseguiram definir o que o Supremo faz, sendo que $19 \%$ disseram que ele fiscaliza e controla os outros poderes do Estado (Legislativo e Executivo), $16 \%$ disseram que ele é a última instância do Poder Judiciário e $10 \%$ que ele julga a constitucionalidade das leis. O survey entrevistou 1.400 brasileiros a partir de 18 anos residentes em áreas urbanas. 
OPINIÃO PÚBLICA, Campinas, vol. 18, n², novembro, 2012, p. 337-354

\section{Referências Bibliográficas}

Caldeira, G. A. and GiBSon, J. L. "The Etiology of Public Support for the Supreme Court". American Journal of Political Science, 36, p. 635-664, 1992.

Cunha, L. G. ; Bueno, R. D. L. S.; Oliveira, F. L.; MoritA, R. Índice de Confiança na Justiça. Relatório ICJBrasil - $3^{\circ}$ Trimestre / 2010. $2^{\text {a }}$ Onda - Ano 2. Disponível em:

<http://virtualbib.fgv.br/dspace/bitstream/handle/10438/7727/RellCJBrasil3tri2010'. pdf? sequence=3>. Acesso em 22 dez. 2010.

FALCÃo, J. A. Cultura Jurídica e Democracia: a favor da democratização do Judiciário. In: LAMOUNIER, B. et al (orgs.). Direito, Cidadania e Participação. São Paulo, T.A. Queiroz, 1980.

O Judiciário segundo os brasileiros. In: GuerRa, S. (Org.). Transformações do Estado e do Direito: novos rumos para o Poder Judiciário. Rio de Janeiro: Editora FGV, p. 13·29, 2009.

Falcão, J. A. e Oliveira, L. "O Supremo e a Opinião Pública". Revista Conjuntura Econômica, vol. 65, n² 2, p. 58.60, 2011.

IPEA. SIPS - Sistema de indicadores de Percepção Social. Justiça. Disponível em: <http://www.ipea.gov.br/portal/images/stories/PDFs/SIPS/101117_sips_justica.pdf>.

Machado, M. B. Reforma do Judiciário e Cidadania. In: Araujo, A. B. (org.). O Brasil no Fim do século: Desafios e Propostas para a Ação Governamental. Rio de Janeiro: IPEA, p. 123·128, 1994.

MARChetTI, V. "Governança Eleitoral: o modelo brasileiro de Justiça Eleitoral”. Dados, Rio de Janeiro, vol. 51, p.865.893, 2008

"A ficha limpa no contexto da governança eleitoral brasileira". Interesse Nacional, n 12, p. 33.42, 2011.

MARChettı, V e CoRtez, R. "A judicialização da competição política: o TSE e as coligações eleitorais". Opinião Pública, vol. $15, n^{\circ} 2$, p. $422 \cdot 450,2009$.

Moısés, J. A. "A desconfiança nas instituições democráticas”. Opinião Pública, vol. 11, n 1, p. 33.63, 2005.

2010

Democracia e confiança: Por que os cidadãos desconfiam das instituições públicas? São Paulo: Edusp,

MoIsÉs, J. A. E CARneIRo, G. P. "Democracia, desconfiança política e insatisfação com o regime: o caso do Brasil". Opinião Pública, vol. 14, n 1, p. 1.42, 2008.

OLIVEIRA, L. and PAGE, B. Do community kitties work?, 2008. Disponível em: $<$ http://www.localgov.co.uk/index.cfm?method=news.detail\&id=72872>

PereiRA, C. and TAYLoR, M. Clean Slate Law: Raising Accountability in Brazil, 2010. Disponível em: <http://www.brookings.edu/opinions/2010/1222_brazil_corruption_pereira.aspx>. Acesso em: 22 dez. 2010.

PesquISA AmB. Perfil do eleitor brasileiro, 2010. Disponível em: <http://www.amb.com.br/docs/pesquisa/PerfilEleitor. AMB.pdf>. Acesso em: 22 dez. 2010.

SADEK, M. T. O Judiciário em Debate. São Paulo: IDESP, 1995.

“Judiciário: mudanças e reformas". Estudos Avançados, vol.18, n 51, p. 79-101, 2004.

United Nations. Comission on Human Rights. Civil and Political Rights, including the questions of independence of the judiciary, administration, of justice, impunity: Report of the special Rapporteur on the independence of judges and lawyers. New York: United Nations, 2005. Disponível em: <http://acnudh.org/wp-content/uploads/2011/01/Report-of the-SR-on-the-independence-of-judges-and-lawyers-Mission-to-Brazil-2005.pdf>.

Joaquim Falcão - joaquim.falcao@fgv.br

Fabiana Luci de Oliveira·luci.oliveira@fgv.br
Recebido para publicação em março de 2011. Aprovado para publicação em agosto de 2011. 